\title{
1. Hopeful organizing in the crucible of the interregnum
}

\section{Karl E. Weick}

The unsettling gap known as an "interregnum" seems formidable, which may make it hard to see that it can be scaled down as well as up. The combination of an old dying order, intermediate flux filled with despair and possibilities, and an ineffable new order suggests that the gap between the old and the new is an interwoven mixture of hope, fear, and imagination. Equivalent structures are visible at more micro levels such as those associated with organizing in extreme contexts (Hällgren et al., 2018). It is the extremity of these latter contexts, as well as the progression of decline, confusion, and redoing, that makes it possible to use the micro example of organizing for high reliability (e.g. Ramanujam and Roberts, 2018) to see into the workings of hope in a macro interregnum.

Our working definition of hope is Rorty's modest description of hope as "imagined conjectures addressing specific purposes" (quoted in Carlsen et al., 2012, p. 294). The following discussion is grounded in losses of the old order in events such as the collapse of the roof over the B\&O Railroad Museum and the destruction of several irreplaceable artifacts (Christianson et al., 2009), air traffic control thwarted by non-standard communication (Weick, 1990), and flawed pediatric heart surgery fostered by hubris and a slow learning curve (Weick and Sutcliffe, 2003). These examples focus on decline and a resulting gap of variable duration, but they are less clear about a new order. That lack of clarity is not unique to micro losses since it is also found in a macro interregnum.

The interregnums (plural) experienced in these more localized extreme settings are episodic, bounded, and transient, yet they retain the basics of a pause between regimes. They retain the fact of uncertainty, the felt intensity of important moment(s), the tenuous balancing of fear and hope, and the necessity to reconstitute an evolving present. Both organizing itself and foresight into a provisional order are reconstituted. The organizing takes the form of "reconstituting," and the "evolving present" is the provisional order. An evolving present can range from a heightened resolve 
to articulate and move toward utopias to a similar resolve to move toward more modest improvements.

Here is a sample of what we can learn about organizing in the interregnum when we watch people engage in reliability seeking.

First, when people engage with extreme contexts, their organizing is more like a stance than a place (organization). The stance is a disposition of activity guided by a grammar of rules and conventions that establish coordinated common ground (Weick, 1979, p. 3). In other words, the stance embodies shared recipes for action and interpretation. This means that hoping tends to be woven into the common ground of the conventions and the recipes. For example, a stance for managing in the face of threatening disruptions has been conceptualized as mindful organizing. This form of organizing is composed of a preoccupation with failure, a reluctance to simplify, a sensitivity to operations, a commitment to resilience, and a deference to expertise (Weick et al., 1999; Weick and Sutcliffe, 2015; Sutcliffe, 2018). Hope is embedded in this mindful stance in the form of resilience to keep going. Hope is embedded in a serious effort to capture detail rather than to simplify, a capture that opens possibilities and provides resources for imagination. Attention to failures likewise suggests openings, as does deference to expertise. Experts often spot options and possibilities that have been missed or normalized into invisibility. Finally, the stance is anchored by current operations in the present (Busby, 2006).

Second, activity in the gap between the declining old and the ineffable new is made more, not less, complicated by any successful achievement. John Dewey articulated a plausible mechanism. Every accomplishment

effects a new distribution of energies which have henceforth to be employed in ways for which past experience gives no exact instruction. ... From the side of what has gone before achievement settles something. From the side of what comes after, it complicates, introducing new problems and unsettling factors. There is something pitifully juvenile in the idea that "evolution," progress, means a definite amount of accomplishment which will forever stay done, and which by an exact amount lessens the amount still to be done, disposing once and for all of just so many perplexities. (Dewey, [1922] 2008, p. 197)

If this compounding of complications is the case, then hoping is part of a sensitivity to current operations and to the present in general. "[I]nstruction in what to do next can never come from an infinite goal, which for us is bound to be empty. It can be derived only from study of the deficiencies, irregularities and possibilities of the actual situation" (Dewey, [1922] 2008, p. 199). This is why, in extreme contexts, one often hears responders say "I've never seen this before, but I know what to do." Hope animates that sentence. In a macro interregnum, "knowing what to do" can feel like a 
much bigger problem. But it still lurks in the deficiencies, irregularities and possibilities of the actual situation.

Readers may object to Dewey's dismissal of an "empty infinite goal," arguing that ways out of the interregnum are neither infinite nor empty. That may be the case. But it is also the case that those exceptions are formulated and reformulated in an overdetermined present that is also changing.

Third, and again from John Dewey, we see that hopeful organizing is writ small and frequent, but with the capability to foster continued hoping.

In every waking moment, the complete balance of the organism and its environment is constantly interfered with and as constantly restored. . . Life is interruptions and recoveries. ... [A]t these moments of a shifting of activity conscious feeling and thought arise and are accentuated. The disturbed adjustment of organism and environment is reflected in a temporary strife. (Dewey, [1922] 2008, p. 125)

In extreme contexts, whether created by uncontrolled wildland fire or by uncontrolled societal shortcomings, interruptions are abundant. What makes the interregnum a site for hoping is the conscious "accentuation of feeling and thought" produced by interruptions. In extreme contexts, this accentuation uncovers localized fears and options. And, if the organizing is sufficiently mindful, imaginative combinations of what is uncovered can be assembled. If we scale up this assembling to the level of Bauman's interregnum, interferences and accentuations continue to affect whether imagination can render the ineffable less so.

Fourth, G.L.S. Shackle's lovely phrase "haunted equilibrium" (1974, p. 77) captures the active quality of both a micro and a macro interregnum. Even though that interregnum is a gap, it is also an unsteady balancing of despair and hope. What is "haunted" about that equilibrium is that it can lose this balance without warning. Shackle puts it this way: Our adjustments

are to the last degree fragile and unstable, because their basis is inevitably at all times partly figment. ... [This state of affairs is "haunted" because] disillusion can call everything in question. What follows such a collapse must defy analysis, since reason for the time being recognizes its own defeat. ... [This leads] to a new groping for adjustment and eventually to a new equilibrium of this peculiar kind. (1974, p. 77)

And, fifth, the recurring idea of possibilities enacted out of that which is troubling suggests that alertness and attention make a difference in the equilibria of an interregnum. Attention can be partitioned into at least three components. Attention is composed partly of its objects, which 
answer to the question: To what are they attending? Attention is also composed of resources, which answer to the question: With what are they attending? And attention is composed partly of goals, which answer to the question: For what are they attending? (Adapted from Dewey, 1989, pp. 333-340.) While the content of the answers to these questions provides insight into what is occurring in an interregnum, it may be even more crucial to assess the relative development and activation of all three. The interregnum may be a haunted equilibrium, but part of the "disillusion" that Shackle (1974) points to may be traced to a singular preoccupation with to, for, or with what. Pathways out of an interregnum should differ dramatically depending on the preferred component of attending.

To conclude, in the preceding discussion hope has been treated as a verb not a noun, and as a process not a state. The verb and the process can be generalized across levels of analysis and can connect macro and micro, at least in theory. Disruptions in an old order accentuate flux, thought, and feeling, which can be interwoven with hoping, thereby altering an evolving present. The very fact of interweaving makes it tough (and artificial) to pull apart an interregnum and focus on hope alone. It could be argued that the very inseparability of hoping is the feedstock of longing.

While the future is something of a mystery, what is less of a mystery is that it will be perceived from a stance in the present. That present stance matters a great deal. It can enrich an interregnum, a possibility that is evident in John Dewey's categorical imperative: "So act as to increase the meaning of present experience. ... [S]tudy the needs and alternative possibilities lying within a unique and localized situation. . . . Till men give up the search for a general formula of progress they will not know where to look to find it" (Dewey, [1922] 2008, p. 196). 